\title{
SISTEM DINAMIS PENILAIAN KINERJA PRODUKSI TEH KEBUN BANTARAN PT PERKEBUNAN NUSANTARA XII
}

Dynamic System Performance Measurement of Tea Production at The Bantaran Plantation Area PT Perkebunan Nusantara XII

\author{
Aulia Brilliantina $^{1) *}$, Bambang Herry Purnomo ${ }^{2)}$, Ida Bagus Suryaningrat ${ }^{2)}$ \\ ${ }^{1)}$ Teknologi Industri Pangan, Politeknik Negeri Jember \\ Jl. Mastrip PO BOX 164 Jember, Indonesia \\ ${ }^{2)}$ Magister Teknologi Agroindustri, Fakultas Teknologi Pertanian, Universitas Jember \\ Jl. Kalimantan No. 37 Kampus Tegalboto Jember 68121, Indonesia \\ *E-mail: brillianthq@gmail.com
}

\begin{abstract}
In the last ten years, the performance of Indonesia's tea agroindustry has been decreased. It is shown by the decreasing of tea estate area as much as 2.18 percent per year, tea production decreased as much as 0.8 percent, and export volume decreased as much as 1,07 percent per year. This study were aimed to identify performance measurement results of tea production at Bantaran plantation area PT Perkebunan Nusantara XII based on the achievement of RKAP and evaluated the performance achieved through the production of tea agroindustry by dynamic system method. This method allowed to conduct comprehensive studies to study the behavior and improved system performance. This study was started from the observation, interviews, and document collection, which then was made causal loop diagram to the simulation model creation and validation of the model made. From the simulation, it came with conclusion, if there was no policy change, then Bantaran plantation area had a decreased performance status.
\end{abstract}

Keywords: tea production, dynamic system, performance measurement

\section{PENDAHULUAN}

Teh adalah salah satu minuman yang paling banyak dikonsumsi dunia. Indonesia saat ini adalah produsen teh terbesar ketujuh di dunia. Temperatur dan kelembaban yang konstan adalah keadaan ideal untuk pertumbuhan tanaman teh. Kondisi tersebut dapat ditemukan di wilayah iklim tropis dan subtropis di Asia tempat lebih dari $60 \%$ teh dunia diproduksi. Dataran tinggi yang dingin merupakan tempat paling baik untuk memproduksi daun teh berkualitas tinggi.

Komoditas teh memiliki peranan penting dalam perekonomian nasional yaitu sebagai sumber pendapatan petani, penyerapan tenaga kerja, sumber devisa negara, mendorong agroindustri pengembangan wilayah dan pelestarian lingkungan. Pada umumnya tanaman teh nasional dikembangkan di Indonesia sejak jaman Belanda. Khusus untuk teh rakyat mulai dikembangkan sekitar Tahun 1980an sehingga kondisi tanaman pada umumnya merupakan tanaman tua/rusak dengan produktivitas yang sudah menurun dan sudah saatnya dilakukan perbaikan budidaya melalui rehabilitasi dan intensifikasi tanaman (Kementerian Pertanian, 2013).

Produksi teh Indonesia Tahun 2015 dengan wujud daun kering sebesar 154.598 ton, dimana merupakan produksi dari Perkebunan Rakyat (PR), Perkebunan Besar Negara (PBN) dan Perkebunan Besar Swasta (PBS). Produksi teh di Indonesia sebagian besar berasal dari Jawa Barat dengan kontribusi produksi (rata-rata lima tahun terakhir) sebesar $66,67 \%$ sedangkan provinsi lainnya hanya berkontribusi kurang dari 10\%. Produksi teh di Indonesia tahun 2016 diperkirakan 
sebesar 154.688 ton dan terus menurun hingga tahun 2020 dengan produksi sebesar 153.970 ton. Rata-rata penurunan produksi teh selama lima tahun ke depan (2016-2020) diperkirakan sebesar 0,11\% per tahun (Sekjen Kementan, 2016).

Menurunnya produksi teh Indonesia kini terjadi karena belum dapat diatasinya masalah-masalah yang dihadapi oleh teh Indonesia, seperti rendahnya produktivitas tanaman karena dominannya tanaman teh rakyat yang belum menggunakan benih unggul, terbatasnya penguasaan teknologi pengolahan produk dan belum mampunya petani mengikuti teknologi yang telah direkomendasikan (Good Agriculture Practice/GAP dan Good Manufacture Process/GMP) serta standar kualitas produk sebagaimana disyaratkan oleh ISO (Kementerian Pertanian, 2014).

Tujuan dari penelitian ini adalah membuat model dinamis penilaian kinerja produksi teh pada Kebun Bantaran PT Perkebunan Nusantara XII dengan mempelajari perilaku dari produksi teh sehingga dapat dirumuskan skenario kebijakan untuk meningkatkan kinerja produksi teh. Adanya peningkatan kinerja produksi teh diharapkan dapat membuat Indonesia memegang posisi penting dalam komoditi teh di dunia kembali.

\section{METODE PENELITIAN}

\section{Kerangka pemikiran}

Sistem penilaian kinerja produksi teh merupakan proses dinamis, hal itu dapat dilihat dari adanya proyeksi ukuran kinerja yang tertuang dalam Rencana Kerja dan Anggaran Perusahaan (RKAP) manajemen pada tahun-tahun mendatang guna meningkatkan kinerja produksi teh menjadi lebih baik dari sebelumnya. Upaya meningkatkan kemampuan dalam melihat tren kinerja di masa mendatang dapat dilakukan dengan mengenali pola permasalahan ukuran kinerja di masa lalu. Integrasi model sistem penilaian kinerja dengan pendekatan sistem bersifat dinamis digunakan untuk meningkatkan kinerja di masa mendatang. Keluaran dari integrasi ini adalah sebuah sinergi untuk menghasilkan model sistem penilaian kinerja yang lebih baik dengan bantuan simulasi komputer. Penggunaan simulasi untuk membantu melihat efektifitas rumusan skenario kebijakan sebelum rumusan tersebut diujicobakan dalam kondisi yang sesungguhnya.

Pendekatan sistem dinamis (SD) merupakan metodologi yang berangkat dari paradigma berpikir sistemik untuk melihat keterkaitan antar variabel kunci kinerja yang menjadi acuan kesuksesan PT Perkebunan Nusantara XII. Identifikasi parameter dan variabel kunci, dan nilai estimasi parameter menggunakan acuan model Performance Measurement Questionnaire (PMQ) (Dixon et al., 1990).

\section{Metode Analisis}

Data primer dan data sekunder yang telah dikumpulkan, diolah menjadi suatu rancangan model dengan menggunakan metodologi sistem dinamis. Dalam menyusun model sistem dinamis tersebut digunakan program komputer dengan software Powersim. Software tersebut digunakan dalam pembuatan diagram simpal kausal dan diagram alir dari sistem penilaian kinerja yang dikaji, pada tahapan pengembangan model, tahapan pengujian asumsi model, serta tahapan simulasi.Estimasi nilai parameter menggunakan plot data analisis regresi dan fungsi-fungsi statistik diolah dengan perangkat lunak Minitab 14, serta Microsoft Excel untuk mengolah beragam fungsi aritmatika dasar.

Sistem dinamis adalah metodologi yang digunakan untuk memahami permasalahan yang kompleks dimana elemen-elemennya saling terkait dan dinamis. Model sistem dinamis didasarkan atas filosofi kausal (sebab akibat) untuk mendapatkan pemahaman yang mendalam tentang sistem. Metodologi ini dititikberatkan pada pengambilan kebijakan dan bagaimana kebijakan 
tersebut menentukan tingkah laku sistem yang dimodelkan secara kuantitatif (Eriyatno, 1998).

\section{Model dinamis penilaian kinerja produksi teh}

Diagram sebab akibat sistem penilaian kinerja produksi teh ditunjukkan pada Gambar 1. Diagram sebab akibat merupakan gambaran hubungan antar variabel yang membentuk rantai sebab akibat dan umpan balik antar variabel. Dari Gambar 1 dapat diketahui, bahwa produksi teh sangat dipengaruhi oleh jumlah petik angkut bahan baku berupa pucuk teh yang dihasilkan dari lahan. Sedangkan petik angkut sendiri dipengaruhi oleh luas lahan perkebunan teh, dan tingkat produktivitas tanaman teh. Dalam produksi teh, hal terpenting yang menjadi indikator kunci penilaian kinerja terdapat pada jumlah produktivitas tanaman serta jumlah mutu I yang dihasilkan. Model proses produksi menjelaskan beberapa variabel yang sangat berpengaruh dalam menentukan hasil dari rendemen produksi teh yang dihasilkan. Rendemen produksi teh merupakan variabel yang menjadi area kesuksesan dalam sub model proses produksi, sebab rendemen produksi teh ini yang akan sangat mempengaruhi profit dari agroindustri teh. Produksi teh sendiri dibagi menjadi tiga jenis mutu yaitu mutu I, mutu II, dan mutu lokal.

Produksi teh sendiri sangat dipengaruhi oleh laju produksi teh. Laju produksi teh didapatkan dari hasil petik angkut pucuk teh dikalikan dengan rendemen teh. Petik angkut sendiri merupakan hasil dari volume bahan baku kebun dengan hasil pembelian bahan baku dari kebun lain. Pembelian ini dilakukan untuk memenuhi target kinerja jumlah bahan baku yang telah ditetapkan dalam RKAP. Diagram alir model proses produksi dapat dilihat pada Gambar 2.

Variabel produktivitas tanaman yang menjadi area kesuksesan manajemen bagian tanaman agroindustri teh Kebun Bantaran dalam penelitian ini menjadi variabel kunci dalam topik permasalahan karena berpengaruh terhadap perolehan produksi teh (mutu I, mutu II, dan mutu lokal). Variabel produksi teh sendiri berpengaruh terhadap perolehan profit agroindustri teh. Laju produksi teh dipengaruhi oleh jumlah daun teh petik

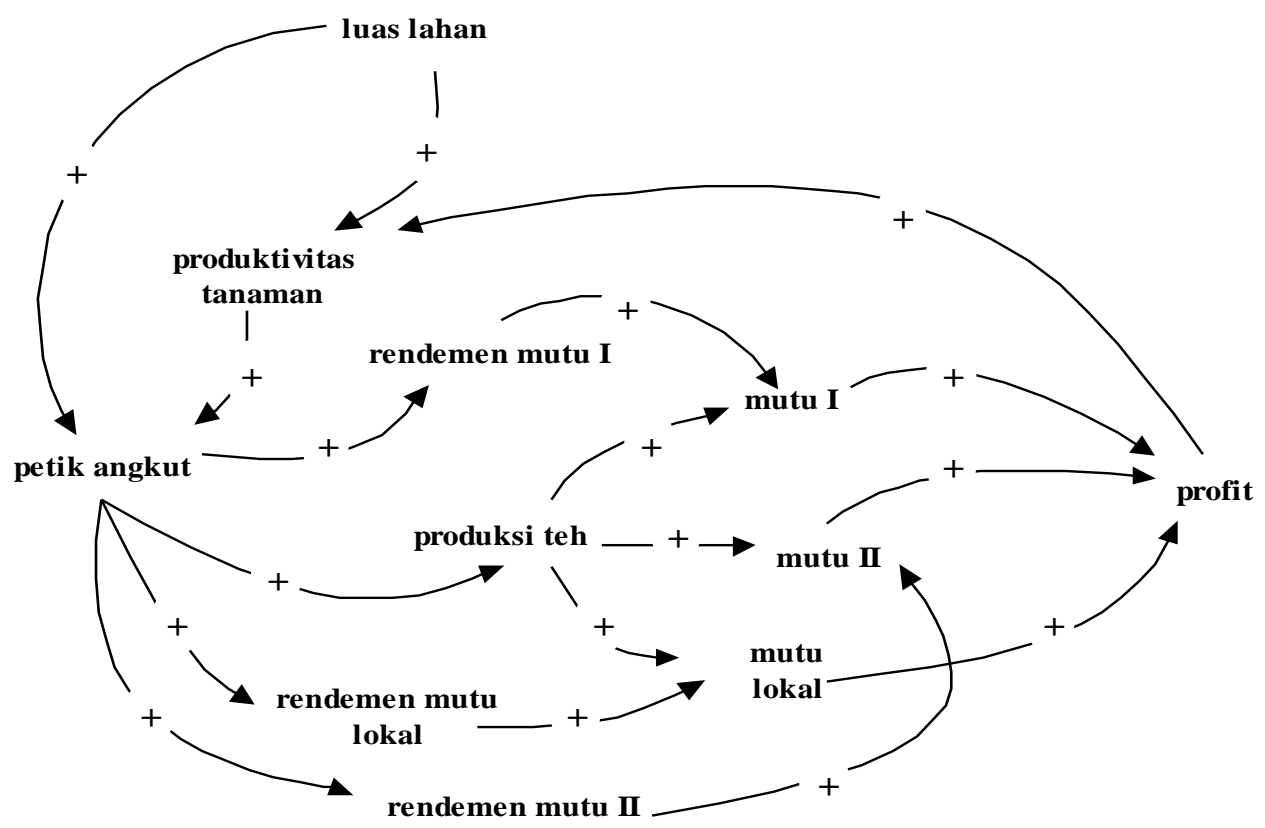

Gambar 1. Diagram sebab akibat sistem penilaian kinerja produksi teh 


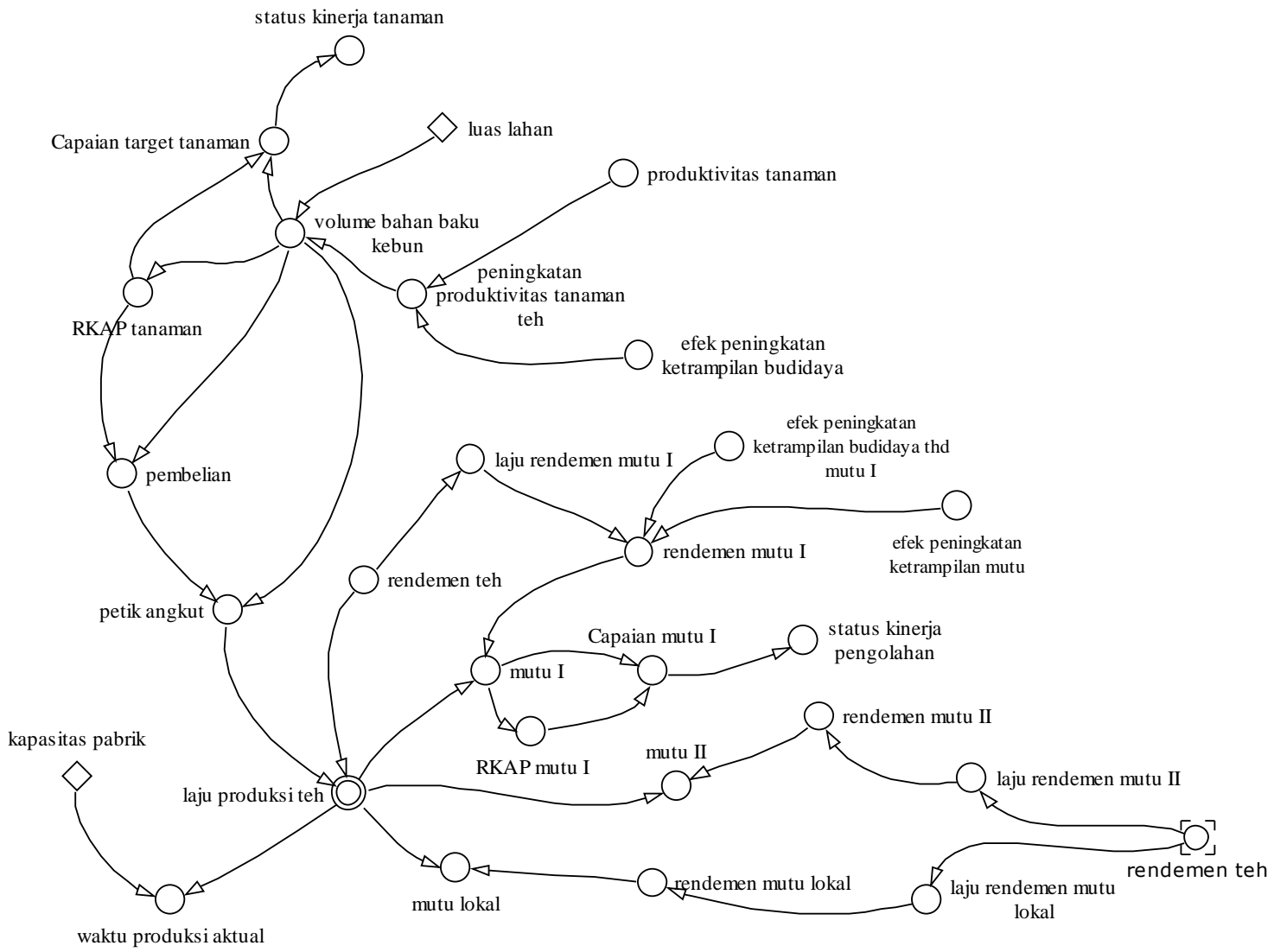

Gambar 2. Diagram alir model proses produksi

angkut (kilogram), yang merupakan hasil penjumlahan volume bahan baku kebun dengan pembelian bahan baku dari kebun lain dikalikan dengan rendemen teh.

Produksi teh mutu I, mutu II, dan mutu lokal merupakan hasil perkalian antara laju produksi teh dengan rendemen dari masing-masing mutu teh yang dihasilkan. Rendemen dari masing-masing jenis mutu teh merupakan nilai dari laju rendemen dari masing-masing jenis mutu teh. Laju rendemen dari masing-masing jenis mutu teh adalah kinerja produksi teh yang dipengaruhi oleh rendemen teh yang dihasilkan.

\section{HASIL DAN PEMBAHASAN}

\section{Validasi Model}

Model divalidasi dengan memandingkan perilaku model dengan sistem nyata (quantitative behaviour pattern comparison) melalui uji MAPE (Mean Absolute Percentage Error). Hasil pengujian konsistensi hasil keluaran menunjukkan bahwa variabel uji memiliki MAPE yang rendah. Nilai MAPE untuk variabel uji produktivitas tanaman dan produksi mutu I berada pada kisaran 9-8\%. Semakin tinggi kompleksitas variabel yang diuji, nilai MAPE akan cenderung semakin besar.

\section{Hasil SimulasiStatus Indikator Kinerja Bagian Tanaman}

Indikator kinerja bagian tanaman mencakup variabel tingkat capaian produktivitas tanaman teh yang didapat dari lahan sendiri yang dijadikan sebagai Key Performance Indikator (KPI). Adapun status KPI bagian tanaman dapat dilihat pada Tabel 1. Tabel tersebut juga menunjukkan bahwa kinerja bagian tanaman agroindustri teh Kebun Bantaran 
tidak mencapai targetnya. Ketidakmampuan agroindustri teh Kebun Bantaran untuk mencapai target kerja dalam hal produktivitas tanaman dapat dikarenakan faktor genetik dari klon yang digunakan, faktor lingkungan seperti iklim dan teknik budidaya (Haq et al., 2013). Seperti yang diketahui bahwa produktivitas tanaman adalah salah satu sifat kuantitatif dari tanaman yang merupakan interaksi genetik x lingkungan (Roy, 2000), jadi faktor genetik dan faktor lingkungan sangat berpengaruh dalam produktivitas tanaman teh.

Tabel 1. Rekapitulasi status KPI bagian tanaman

\begin{tabular}{cccc}
\hline Tahun & $\begin{array}{c}\text { Capaian } \\
\text { Produktivit } \\
\text { as tanaman } \\
(\%)\end{array}$ & $\begin{array}{c}\text { Target } \\
\text { Capaian } \\
\text { Produkti } \\
\text { vitas } \\
\text { tanaman } \\
(\%)\end{array}$ & $\begin{array}{c}\text { Status } \\
\text { Indikator } \\
\text { Kinerja }\end{array}$ \\
\hline 2012 & 80 & 100 & Cukup \\
2013 & 88 & 100 & Baik \\
2014 & 87 & 100 & Baik \\
2015 & 83 & 100 & Baik \\
2016 & 77 & 100 & Cukup \\
2020 & 63 & 100 & Kurang \\
& & 100 & Sangat \\
2025 & 43 & & Kurang \\
\hline
\end{tabular}

Sumber: Hasil analisis data primer (2017)

\section{Hasil Simulasi Status Indikator Kinerja Bagian Teknik dan Pengolahan}

KPI bagian teknik dan pengolahan adalah variabel jumlah nilai rendemen dari produksi teh, terutama capaian dari jumlah rendemen mutu I. Adapun status indikator kinerja bagian akuntansi dan umum khususnya bagian SDM dari agroindustri teh Kebun Bantaran dapat dilihat pada Tabel 2. Capaian produksi mutu I tidak mencapai target, bahkan setiap tahunnya cenderung terjadi penurunan mutu I (Tabel 2). Turunnya mutu teh yang dihasilkan dapat dikarenakan kesalahan pada proses pemetikan. Sebagaimana yang dinyatakan oleh Sukasman dan Johan (1990), bahwa kesalahan petik merupakan salah satu penyebab rendahnya hasil pucuk teh. Sukasman (1992) menyatakan bahwa pada pemetikan rata dengan lebih $70 \%$ pucuk dipetik pada kepel, setelah kira-kira 6 bulan hasil dan kwalitas pucuk akan menurun karena tanaman akan menderita kekurangan keseimbangan karbohidrat. Selain itu penurunan mutu dapat dikarenakan proses pengolahan tidak dilakukan sesuai SOP.

Tabel 2. Rekapitulasi status KPI bagian pengolahan

\begin{tabular}{|c|c|c|c|}
\hline Tahun & $\begin{array}{c}\text { Capaian } \\
\text { Produksi } \\
\text { Mutu I } \\
(\%)\end{array}$ & $\begin{array}{c}\text { Target } \\
\text { Capaian } \\
\text { Produksi } \\
\text { Mutu I (\%) }\end{array}$ & $\begin{array}{c}\text { Status } \\
\text { Indikator } \\
\text { Kinerja }\end{array}$ \\
\hline 2012 & 90,63 & 100 & Sangat Baik \\
\hline 2013 & 76,98 & 100 & Cukup \\
\hline 2014 & 69,40 & 100 & Kurang \\
\hline 2015 & 70,02 & 100 & Cukup \\
\hline 2016 & 57,85 & 100 & $\begin{array}{l}\text { Sangat } \\
\text { Kurang }\end{array}$ \\
\hline 2020 & 53,30 & 100 & $\begin{array}{l}\text { Sangat } \\
\text { Kurang }\end{array}$ \\
\hline 2025 & 46,07 & 100 & $\begin{array}{l}\text { Sangat } \\
\text { Kurang }\end{array}$ \\
\hline
\end{tabular}

Sumber: Hasil analisis data primer (2017)

Berdasarkan hasil simulasi hasil status kinerja produksi teh Kebun Bantaran dapat dirumuskan beberapa prioritas yang dapat dijadikan rekomendasi kebijakan. Rumusan kebijakan berhubungan dengan hal-hal yang menjadi parameter yang diuji pada model yang mempunyai korelasi signifikan terhadap parameter utama (produktivitas tanaman), yaitu peningkatan peremajaan tanaman. Rumusan kebijakan kinerja peningkatan peremajaan dapat diupayakan melalui cara, yaitu:

1. Meningkatkan populasi tanaman teh yang unggul dengan penyulaman.

2. Percobaan area mekanisasi pemetikan sebesar 20\% dari luas area agroindustri teh, dengan penggunaan mesin petik dapat meningkatkan pembentukan bidang petik.

3. Pemangkasan tanaman teh secara rutin yaitu berkisar antara 3-4 tahun. 
4. Dilakukan pemetikan selektif secara manual pada pucuk-pucuk yang sudah manjing lebih awal sebelum petik mesin jika rotasi yang digunakan selama 60 hari. Pemetikan selektif sebaiknya dilakukan setiap 30 harian.

\section{KESIMPULAN}

Hasil simulasi model dinamis penilaian produksi teh menunjukkan bahwa produksi teh Kebun Bantaran memiliki status kinerja yang semakin tahun semakin menurun. Model dinamis penilaian kinerja produksi teh dapat membantu pihak manajemen agroindustri teh Kebun Bantaran dalam merumuskan kebijakan pada tahun mendatang sesuai RKAP perusahaan. Rumusan kebijakan yang mempunyai korelasi signifikan terhadap parameter utama (produktivitas tanaman) yaitu peningkatan peremajaan tanaman.

\section{DAFTAR PUSTAKA}

Dixon, Robb J., Alfred J. Nanni, Jr., and Thomas E. Vollmann. 1990. The New Performance Challenge: Measuring Operations for WorldClass Competition. DowJones Irwin, IL.

Eriyatno. 1998. Ilmu Sistem: Meningkatkan Mutu dan Efektifitas Manajemen. IPB Press, Bogor.

Haq, Muthia Syafika dan Karyudi. 2013. Upaya peningkatan produksi teh (Camelia sinensis (L) O. Kuntze) melalui penerapan kultur teknis. Warta PPTK, 24 (1): 71-84.

Kementerian Pertanian. 2013. Pedoman Pelaksanaan Pengelolaan Data Komoditas Perkebunan (PDKP). Direktorat Jenderal Perkebunan Kementerian Pertanian, Jakarta.
Kementerian Pertanian. 2014. Perkembangan Pasar Teh Indonesia di Pasar Domestik dan Pasar Internasional. Balai Penelitian Tanaman Industri dan Penyegar Kementerian Pertanian, Jakarta.

Roy, D. 2000. Plant Breeding, Analysis and Exploitation of Variation. Narosa Publishing House, New Delhi.

Sekjen Kementan. 2016. Outlook Teh Komoditas Pertanian Subsektor Perkebunan. Pusat Data dan Sistem Informasi Pertanian, Jakarta.

Sukasman. 1992. Manfaat Pohon Pelindung bagi Tanaman Teh. Warta Pusat Penelitian Teh dan Kina, 8 (1): 9-15. 